\title{
Contributions of remote sensing in the diachronic study of the spatial and temporal evolution of the Ahmed El Hansali dam water reservoir from 2002-03 to 2018-19.
}

\author{
TarikEl Orfi ${ }^{1,2^{*}}$, MohamedEl Ghachi ${ }^{1}$ and SébastienLebaut ${ }^{2}$ \\ 1 “LDRH” Laboratory, Sultan Moulay Slimane University, B.P: 524, Beni Mellal, Morocco \\ 2 “LOTERR” Research Unit, Lorraine University, 57000 Metz, France
}

\begin{abstract}
The OumErRbiabasin is one of the watersheds with the largest number of hydraulic infrastructures in Morocco. These hydraulic structuressupply water for drinking, industrial and agricultural uses. The Ahmed El Hansali dam is a $740 \mathrm{Mm}^{3}$ reservoir located near Zaouyat Cheikh andhave an active storage of $473 \mathrm{Mm}^{3}$. The succession of dry years in the OumErRbiabasin has had a negative impact on the water resource and has caused a remarkable decrease in the reservoir of the Ahmed el Hansali dam. In this paper, the MNDWI (Modified Normalized Difference Water Index) from Landsat 5-TM, Landsat 7-ETM, and Landsat 8-OLI satellite images was used to estimate the spatial and temporal fluctuations of the volumes of water stored in the reservoir between hydrological years 2002-03 and 2018-19. Results show that the volumes estimated by remote sensing reasonably match the volumes estimated by the OumErRbia Hydraulic Basin Agency (OERHBA)using recorded water levels and reservoir storage curve for years 2002-03 and 2013-14; the determination coefficient $\mathrm{R}^{2}$ exceeds 0.90 . The mapping of the extent of the dam's impoundment has shown a very significant decreasein the flooded area level during dry years.
\end{abstract}

\section{Introduction}

Water is a natural resource that is essential for human well-being and sustainable socioeconomic development [1]. In Morocco, water management is even more vital because of the arid to semi-arid climate and limited water availability. Over the past three decades, Morocco has suffered five periods of severe drought [2], which have exacerbated several problems and underlines the seriousness of water scarcity in the country.

Storage is often advocated as a solution to droughts, as it allows us to build up reserves with the water available in rainy periods (winter) and mobilize them during the dry period [3]. To meet growing water needs, Morocco has built an extensive network of hydraulic infrastructure spread over the entire hydrographic network [4]. Morocco's water resources policy has long been oriented towards the construction of dams [5]. The late Majesty

\footnotetext{
*Corresponding author:elorfitarik@gmail.com
} 
Hassan-II initiated the development of large dams as early as 1967, the main objective being ensuring food security and guaranteeing drinking water supply to the population [6]. Morocco's various development plans have always given priority to the agricultural sector, and large agriculturalhydraulicinfrastructures have always beenperceivedby Moroccan officials as the pillar of economic development[7].

Rational management of water resources must ensure continuous availability in quantity and quality. In this respect, the Master Plan for Integrated Water Resources Management (MPIWRM) was proposed to plan water resources development based on a prospective and concerted vision that takes into account, on the one hand, the evolution of resources and, on the other hand, the real water needs [8]. With the largest irrigated perimeters in the Maghreb, some reaching 100000 ha and more than 100 large dams, Moroccois the "country of large hydraulics"[9]. OumErRbia watershed contains several dams, including the Ahmed El Hansalidam "AEH'd" (formerly Dchar El Oued dam). Itis located near the Zaouyat Cheikh centre, and $50 \mathrm{~km}$ from KasbaTadla, and was commissioned in 2002 [6].

Remote sensing shows a great performance in the monitoring of water resources although there are difficulties related to their identification.Day-to-day dam management requires the knowledge of the amount of stored water as well, and the volume of expected inflows in the reservoir to optimally allocate water to local and downstream users. For several decades, an increasing number of satellites are used for the observation of the spatial and temporal variability of several compartments of continental waters (open water, snow cover, soil moisture, etc.) [10]. This study is a contribution to the use of Landsat images in the temporal monitoring of continental water surfaces. It also evaluates the possibility of calculating the volumes related to these surfaces by coupling them to a multisource Digital Elevation Model.

\section{Material and Methods}

\subsection{Study area}

The upper watershed of the OumErRbiariver $\left(3380 \mathrm{~km}^{2}\right)$ is part of the central plateau and the Middle Atlas. It is the upstream part of the large watershed of Oum Er Rbiariver. It is bounded by the Moulouya watershed to the east, the Sebou watershed to the north, and the Bouragreg watershed to the west. The climate station located after AEH'd is used as an outlet (Fig. 1).

Six climate stations are managed by the Agency of the Hydraulic Basin of OumErRbia "OERHBA". The climate is Mediterranean with rainy and mild winters and hot and dry summers.

The annual variability of rainfall between 1974-75 and 2016-17 for three stations representative of the study area shows a decrease in the annual mean from upstream to downstream(Tab. 1)[11]:

Table 1.Principal characteristics of the three representative stations

\begin{tabular}{|c|c|c|c|c|c|c|}
\hline \multirow{2}{*}{ Station } & \multirow{2}{*}{ Elevation } & \multirow{2}{*}{$\begin{array}{l}\text { Mean } \\
(\mathrm{mm})\end{array}$} & \multicolumn{2}{|c|}{ Min } & \multicolumn{2}{|c|}{ Max } \\
\cline { 4 - 7 } & & $\mathrm{R}(\mathrm{mm})$ & Year & $\mathrm{R}(\mathrm{mm})$ & Year \\
\hline Tamchachat & $1685 \mathrm{~m}$ & 692 & 302 & $99-00$ & 1314 & $10-11$ \\
\hline Tarhat & $886 \mathrm{~m}$ & 570 & 290 & $94-95$ & 1117 & $95-96$ \\
\hline Taghzoute & $708 \mathrm{~m}$ & 508 & 260 & $06-07$ & 857 & $95-96$ \\
\hline
\end{tabular}

Hydrologically, the OumErRbia originates from the Fellat wadi, which receives inputs from a group of sources known asthe "sources of OumErRbia". It is only from the 
confluence of Fellat river with BouIdjiriver that the river is called OumErRbia [12]. The flow of the OumErRbia river is perennial and the module at the Tarhat station is of the order of $16 \mathrm{~m}^{3} / \mathrm{s}$.

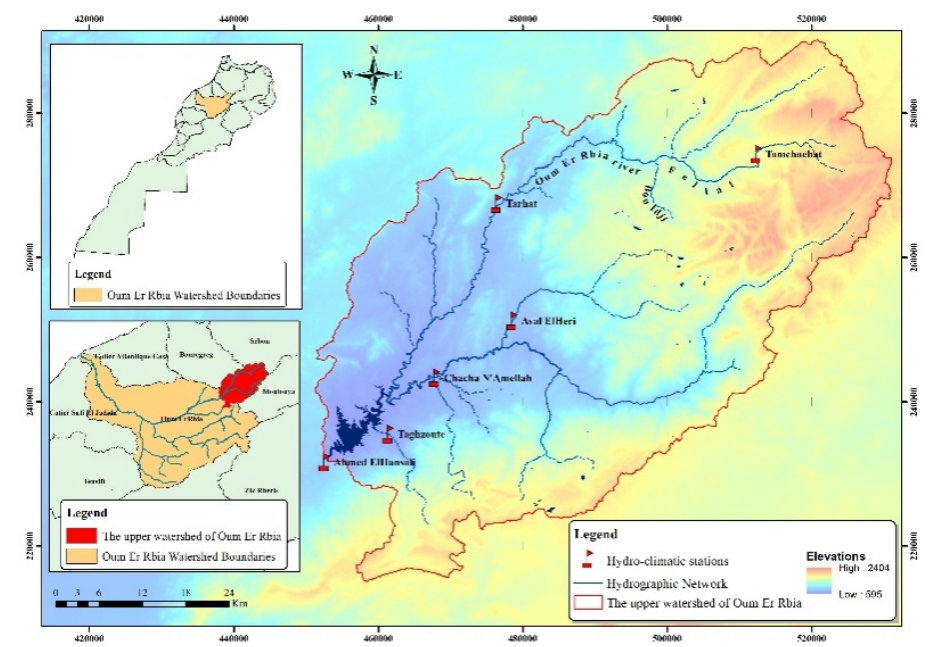

Fig. 1.Geographic location of the study area.

The OumErRbiawatershed is home of 15 dams that provide water for nearly 323000 ha of agricultural land distributed between the Tadla, Tessaout, Haouz and Doukkala perimeters, as well as the production of about $350 \mathrm{Mm}^{3} /$ year ofdrinking water and industrial water supply. The AEH'd(Image 1), commissioned in 2002, is a structure allowing the creation of a reservoir of $740 \mathrm{Mm}^{3}$, to regulate $473 \mathrm{Mm}^{3}$ and to obtain a waterfall varying between 51 and $82 \mathrm{~m}$ for the production of electric power.

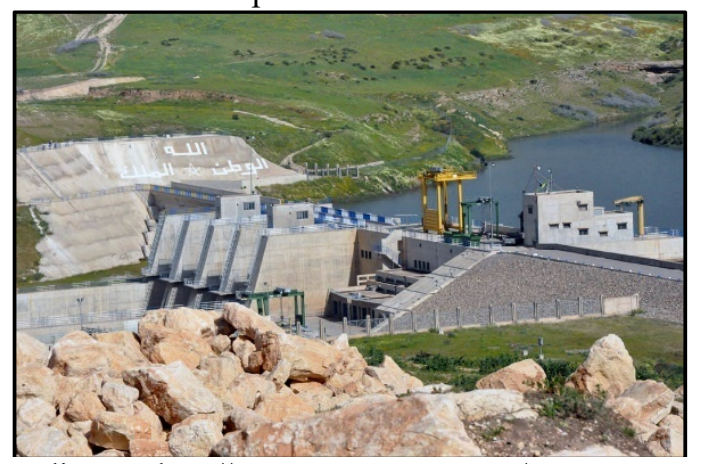

Image. 1. Ahmed El Hansali Dam "http://www.sgtm-maroc.com/"

\subsection{Lake extent estimation and validation}

The temporal evolution of water volumes of the Ahmed El Hansali lake reservoir is done using two sources of information: the extent of the lake is estimated at a monthly timescalefrom Landsat images. The overlay of these boundaries with a multi-source DEM allows the calculation of the volume of water in the dam reservoir. This study adopts an operational geomatics approach (Fig. 2) that is used to delineate and follow the lake's extent and volume using remotely sensed data. 


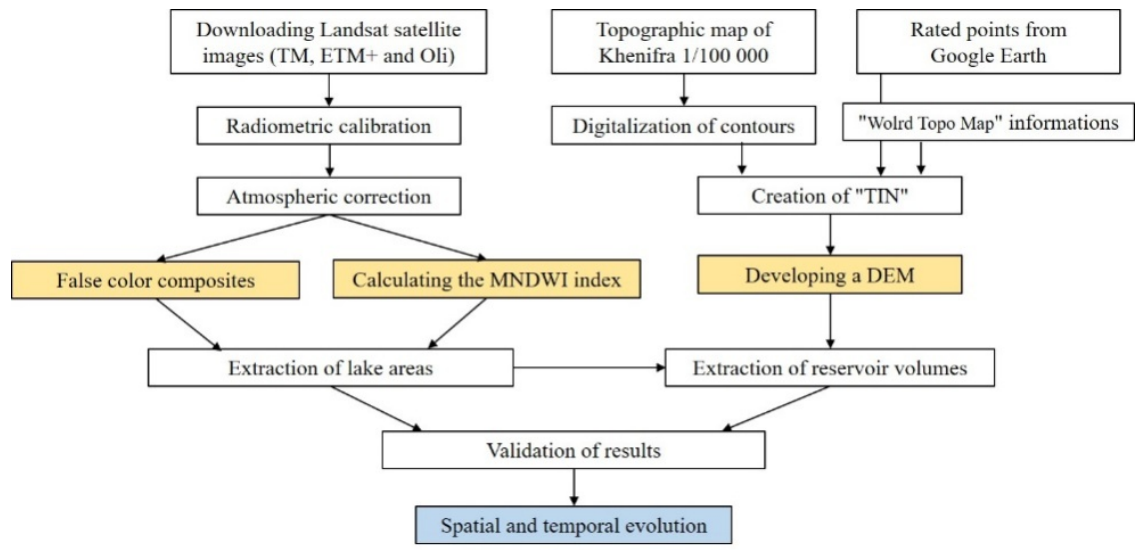

Fig. 2. Flowchart of the methodology for the calculation of the surfaces and volumes of the Ahmed El HansaliLake reservoir.

\subsection{Data}

Landsat satellite images were downloaded since 2000 from the NASA website (https://landsat.gsfc.nasa.gov/). They were preprocessed to have reflectance-calibrated images for the whole series. Radiometric calibration was performed to overcome differences between instrument generations (Tab. 2). The influence of the state of the atmosphere at the time of shooting was removed by an atmospheric correction. Both corrections were performed using the "Radiometric Calibration" and "Dark Subtraction" functions implemented in the ENVI software.

Table 2.Principal characteristics of Landsat satellites (https://landsat.gsfc.nasa.gov/); B: Blue, G: Green, R: Red, NIR: Near Infrared, SWIR: Short Wavelength Infrared, TIR: Thermal Infrared, Pan: Panchromatic, Aer: Aerosol, Cir: Cirrus

\begin{tabular}{|c|c|c|c|c|}
\hline \multicolumn{2}{|c|}{ Satellites } & Landsat-5 & Landsat-7 & Landsat- 8 \\
\hline \multicolumn{2}{|c|}{ Sensors } & TM & ETM+ & OLI - TIRS \\
\hline \multicolumn{2}{|c|}{ Mission period } & $1984-2013$ & 1999-operational & 2013-operational \\
\hline \multirow{11}{*}{ 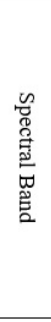 } & Band 1: & $0,45-0,52 \mu \mathrm{m}(\mathrm{B})$ & $0,441-0,514 \mu \mathrm{m}(\mathrm{B})$ & $0,435-0,451 \mu \mathrm{m}$ (Aer) \\
\hline & Band 2: & $0,52-0,60 \mu \mathrm{m}(\mathrm{G})$ & $0,519-0,601 \mu \mathrm{m}(\mathrm{G})$ & $0,452-0,512 \mu \mathrm{m}(\mathrm{B})$ \\
\hline & Band 3: & $0,63-0,69 \mu \mathrm{m}(\mathrm{R})$ & $0,631-0,692 \mu \mathrm{m}(\mathrm{R})$ & $0,533-0,590 \mu \mathrm{m}(\mathrm{G})$ \\
\hline & Band 4: & $0,76-0,90 \mu \mathrm{m}(\mathrm{NIR})$ & $0,772-0,898 \mu \mathrm{m}(\mathrm{NIR})$ & $0,636-0,673 \mu \mathrm{m}(\mathrm{R})$ \\
\hline & Band 5: & $1,55-1,75 \mu \mathrm{m}$ (SWIR1) & $1,547-1,74 \mu \mathrm{m}$ (SWIR1) & $0,851-0,879 \mu \mathrm{m}(\mathrm{NIR})$ \\
\hline & Band 6: & $10,4-12,5 \mu \mathrm{m}$ (TIR) & $10,31-12,36 \mu \mathrm{m}(\mathrm{TIR})$ & $1,566-1,651 \mu \mathrm{m}$ (SWIR1) \\
\hline & Band 7: & $2,08-2,35 \mu \mathrm{m}$ (SWIR2) & 2,064-2,345 $\mu \mathrm{m}$ (SWIR2) & $2,107-2,294 \mu \mathrm{m}$ (SWIR2) \\
\hline & Band 8: & & $0,515-0,896 \mu \mathrm{m}(\mathrm{Pan})$ & $0,503-0,676 \mu \mathrm{m}$ (Pan) \\
\hline & Band 9: & & & $1,363-1,384 \mu \mathrm{m}$ (Cir) \\
\hline & Band 10: & & & $10,60-11,19 \mu \mathrm{m}$ (TIR 1) \\
\hline & Band 11: & & & $11,50-12,51 \mu \mathrm{m}$ (TIR 2) \\
\hline \multicolumn{2}{|c|}{ Resolution } & $\begin{array}{l}\text { General : } 30 \mathrm{~m} \\
\text { TIR : } 120 \mathrm{~m}\end{array}$ & $\begin{array}{l}\text { General : } 30 \mathrm{~m} \\
\text { Pan : } 15 \mathrm{~m} \\
\text { TIR : } 60 \mathrm{~m}\end{array}$ & $\begin{array}{l}\text { General : } 30 \mathrm{~m} \\
\text { Pan : } 15 \mathrm{~m} \\
\text { TIR : } 100 \mathrm{~m}\end{array}$ \\
\hline
\end{tabular}

"OERHBA" providedtime series total volumescalculated using recorded water levels and reservoir storage curvebetween 2002-03 and 2013-14.

\subsection{MNDWI Index}

Water is characterized by a relatively higher reflectance in the visible than in the near and middle infrared. The absorption of solar radiation in the near infrared band is complete. Several water detection indices are based on this phenomenon such as the "NDWI" 
(Normalized difference water index) introduced by McFeeters[13]. This index is used to delineate surface water by the ratio of green to near-infrared reflectance, where $\rho$ is the reflectance.

$$
N D W I=\frac{\rho_{\text {Green }}-\rho_{N I R}}{\rho_{\text {Green }}+\rho_{\text {NIR }}}
$$

In $2006 \mathrm{Xu}$ replaced NIR reflectance with middle infrared reflectance and suggested changing the NDWI nomenclature to MNDWI "Modified Normalized Difference Water Index" [14]. He observed that MNDWI is more accurate in delineating wetlands than NDWI.

$$
M N D W I=\frac{\rho_{\text {Green }}-\rho_{M I R}}{\rho_{\text {Green }}+\rho_{M I R}}
$$

We choose to work with the MNDWI index because several researchers[14-19] have shown that it is the most accurate in discriminating between dry and wet surfaces. A discrimination threshold of zero was set for all treated scenes, however, multispectral images acquired at different times always have different characteristics [16].

\subsection{Lake topography}

To calculate the volume of the lake, it is necessary to know the topography below the surface of the lake. Since the reservoir was commissioned in 2002, the topography of the lake had to be based on previous topographic data. The only source of such homogeneous data is the 1/100000 topographic map of Khenifra (InstitutGéographique National - France, 1972). Digitized contour lines are the basis of the pre-dam topographic information. To increase the accuracy of the final DEM, data from other sources have been merged into a TIN file: elevation points extracted from "Google Earth"and "the world topo map"layer (ESRI). From the latter the DEM with $84 \mathrm{~m}$ spatial resolution was extracted.

\section{Results and Discussion}

\subsection{Evolution of the surface area of AEH'd Lake}

It is difficult to quantify the uncertainty associated with the lake boundaries determined by the MNDWI. An estimate can be made by overlaying our results with high spatial resolution Google Earth imagery (Fig. 3).

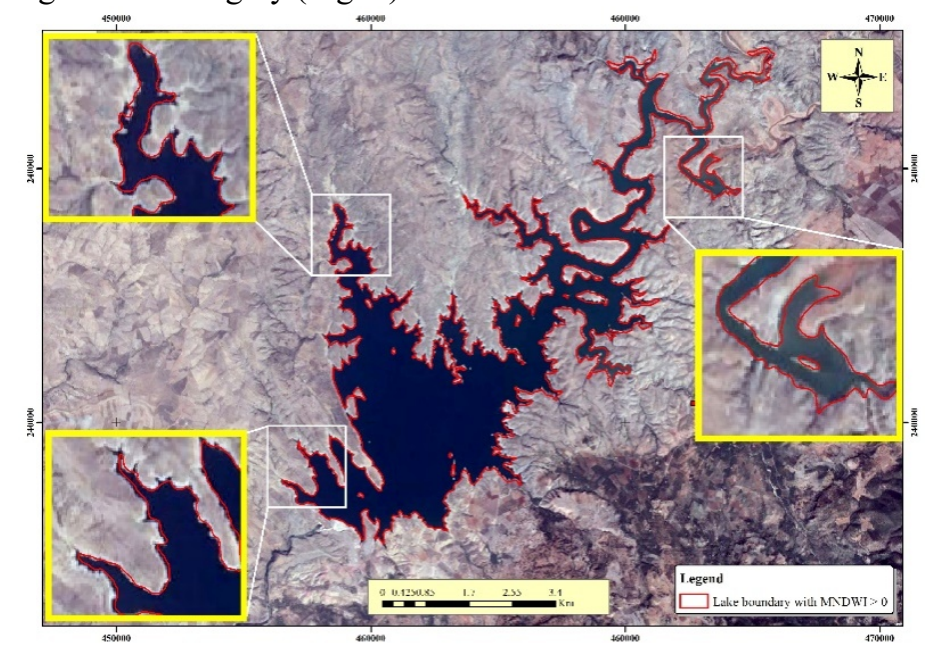


Fig. 3. Overlay of the extent as of 12/24/2013 on a Google Earth image as of 12/31/2013.

On the example of December 2013, the good superposition of the two inundation extents is obvious except on the most pronounced festoons of the shoreline. The MNDWI index is therefore a good predictor of water surfaces in the AEH'd, and the estimated water are reasonable.

During the period of filling of the dam, the surface area of the AEH'd lake increased until June 2004, when it reached $24 \mathrm{~km}^{2}$ (Figs. 4 and 5). Then, and in accordance with the results of the analysis of rainfall series in the study area [11], the increase and retraction of the lake surface follow the annual fluctuations in rainfall. Until 2009, the end of the dry period that began in 1979, the average surface of the lake was $13 \mathrm{~km}^{2}$ (Figs. 4 and 5). From 2009, another homogeneous wetter series begins for which the average surface area of the lake is $22 \mathrm{~km}^{2}$, with a maximum in February 2009, $27.5 \mathrm{~km}^{2}$, following the very heavy rainfall of autumn/early winter 2008/2009. However, since 2018 rainfall has been falling again, bringing the surface of the lake closer to that of the early $2000 \mathrm{~s}$.

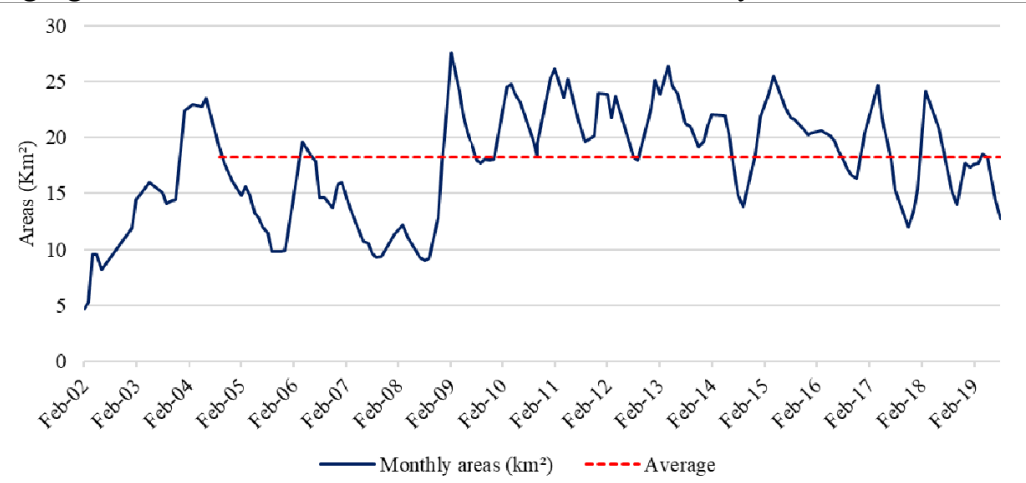

Fig. 4. Evolution of the surface area of AEH'd Lake between 2002-03 and 2018-19.

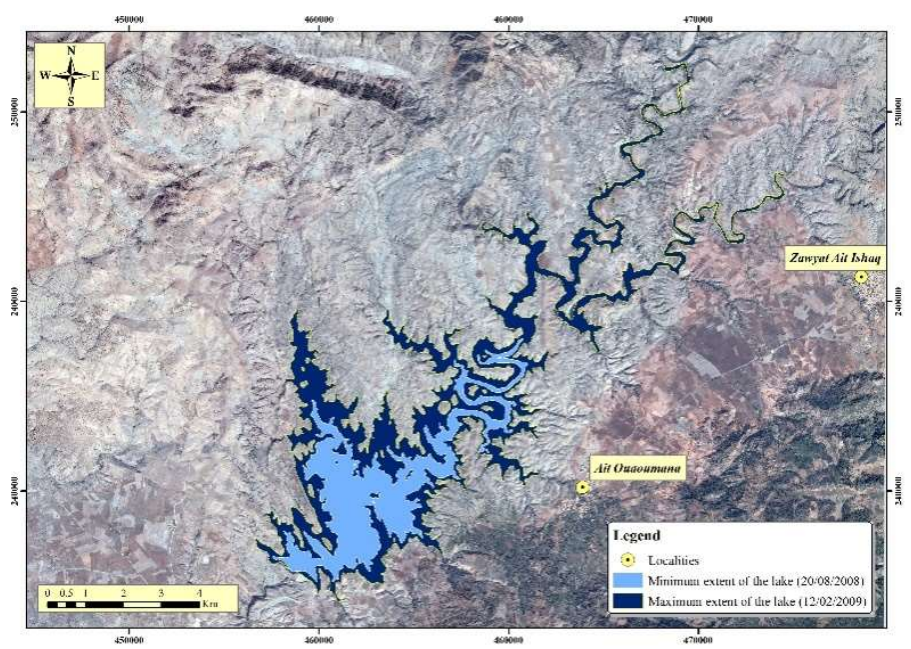

Fig. 5. Minimum and maximum surface area of the lake over the period 2002/2019.

There is also an average annual expansion/retraction cycle of around $8 \mathrm{~km}^{2}$.

On a monthly scale, on average, the filling of the lake begins in November and ends in April $\left(21 \mathrm{~km}^{2}\right)$. From May the reservoir is emptied until October $\left(15 \mathrm{~km}^{2}\right)$ to ensure the 3 types of uses, the main one being agricultural since the Tadla plain located downstream is the first irrigated perimeter in Morocco (Fig. 6). 


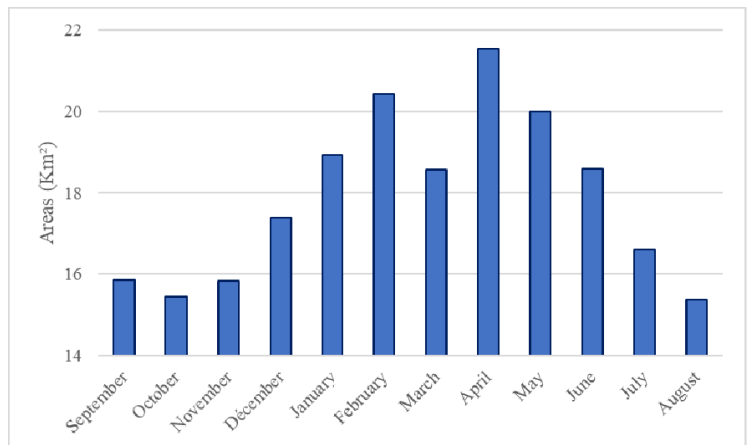

Fig. 6. Evolution of the average monthly surface areas of Lake AEH'd.

\subsection{Evolution of the volume of AEH'd lake between 2002-03 and 2018-19}

The calculation of the lake water volume is based on the pre-dam construction topography described from the $84 \mathrm{~m}$ spatial resolution multisource DEM. The greater the slope of the lake floor, the greater the uncertainty in the volume of water. Slopes, for $82 \%$ of the surface are less than $15 \%$ and only $2 \%$ are greater than $25 \%$ (fig. 8 ). Thus, the system of distribution in the lake is contributes to a low uncertainty on the calculation of the volume; especially since the steepest slopes are located in the upstream part of the lake where it is narrow (fig. 7): the distance from one side to the other of about $300 \mathrm{~m}$ maximum.

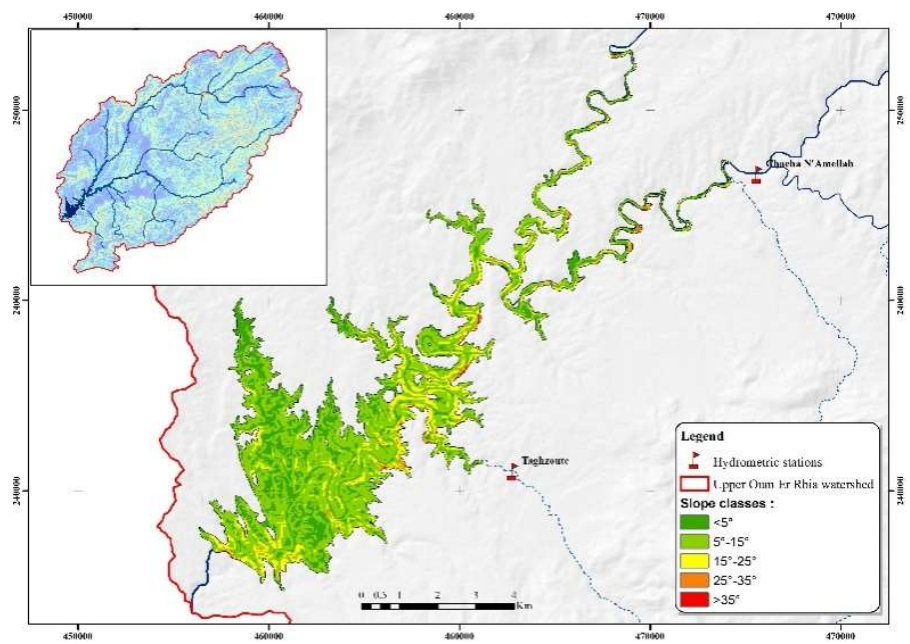

Fig. 7. Slope classes at the maximum extension of the lake.

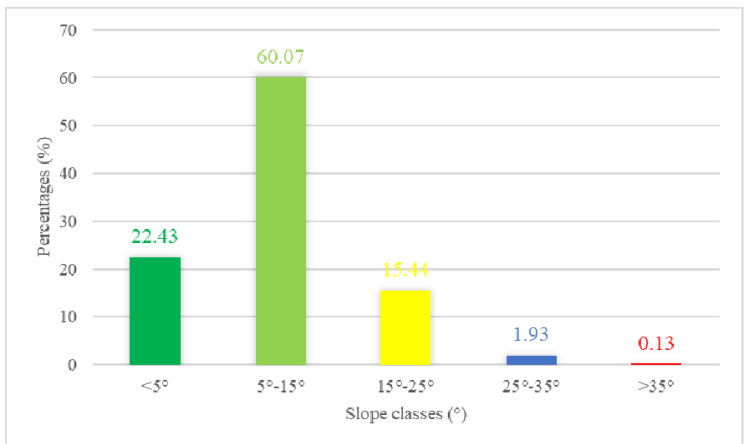

Fig. 8. Histogram of slope classes. 
The validation of water volumes calculated from remote sensing uses the volumes of water measured and provided by the "OERHBA" over the period 2002/2014. Whether on an annual or monthly scale, the results are particularly good with determination coefficients $\left(\mathrm{R}^{2}\right)$ of 0.95 and 0.93 respectively (Figs. 9 and 10).

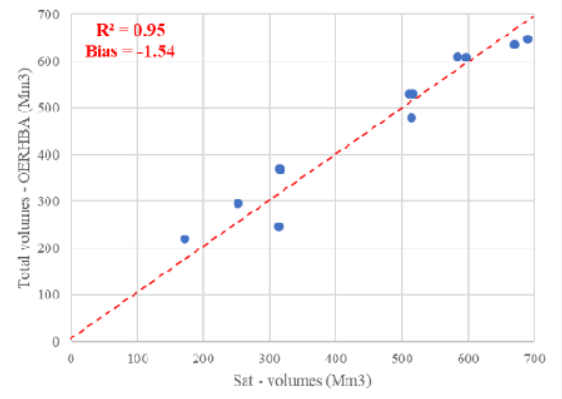

Fig. 9. Annual correlation between Sat-Vol and OERHBA-Vol.

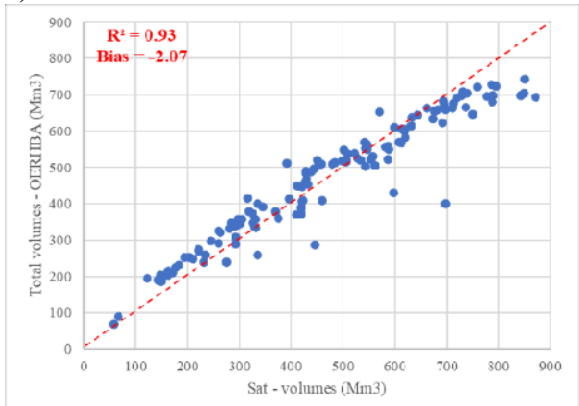

Fig. 10. Monthly correlation between Sat-Vol and OERHBA-Vol.

Although low, the relative bias shows that our methodology leads to an underestimation of the order of $15 \%$ for volumes below $500 \mathrm{Mm}^{3}$ and an overestimation of the order of $10 \%$ for higher values.

On an annual scale, after the filling of the dam, the end of the dry period is accompanied by an almost continuous emptying of the lake until it reaches $171.5 \mathrm{Mm}^{3}$ in $2008 / 2009$ (fig.11). From 2009 onwards, the maximum reserves are reached and are of the order of $650 \mathrm{Mm}^{3}$, dropping below the $500 \mathrm{Mm}^{3}$ threshold in the last two years.

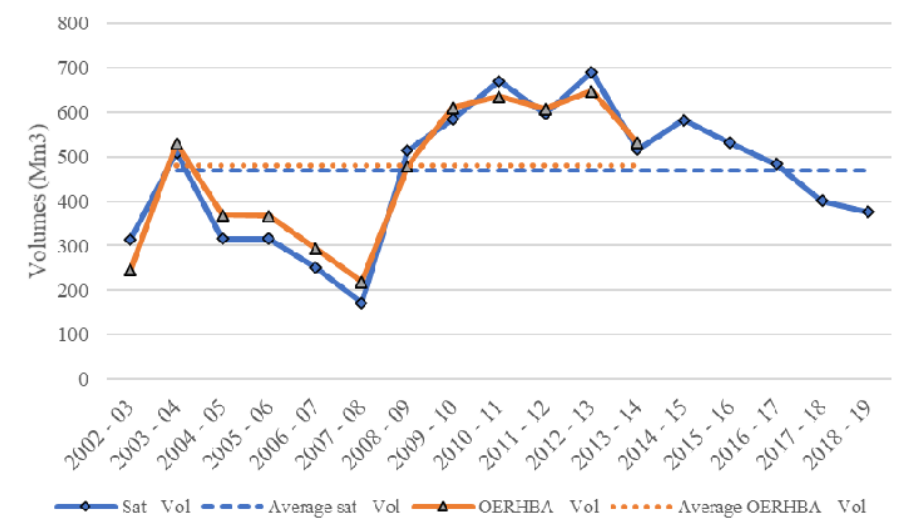

Fig. 11.Maximum annual volume of the AEH'd reservoir between 2002-03 and 2018-19.

On a monthly scale, on average we note that the quantities emptied during the dry period are of the order of $250 \mathrm{Mm}^{3}$. But for the driest periods it is more like $350 \mathrm{Mm}^{3}$ that are used. These results underline the merits of the mega-hydraulic infrastructure in this sector.

In accordance with the evolution of the surface area, the volumes of the reservoir are lower than the average $\left(467 \mathrm{Mm}^{3}\right.$ for Sat - volumes and $471 \mathrm{Mm}^{3}$ for the volumes provided by the "OERHBA") until August 2008 with a minimum for satellite data equal to $144 \mathrm{Mm}^{3}$. Since 2009 , volumes have generally been above average except in recent years where there has been a remarkable decrease in volume. (Fig12). 
The period of filling of the dam begins in December with an increase in volume until April, which records an average volume equal to $620 \mathrm{Mm}^{3}$. During summer, the volume of the reservoir decreases until it reaches $350 \mathrm{Mm}^{3}$ in August (Fig13).

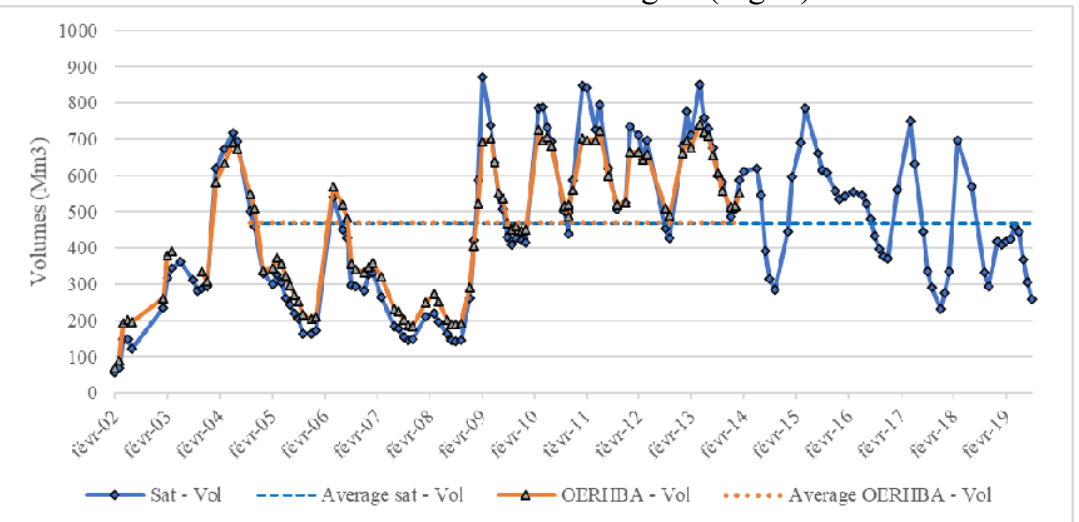

Fig. 12.Monthly volume of the AEH'd reserve between 2002-03 and 2018-19.

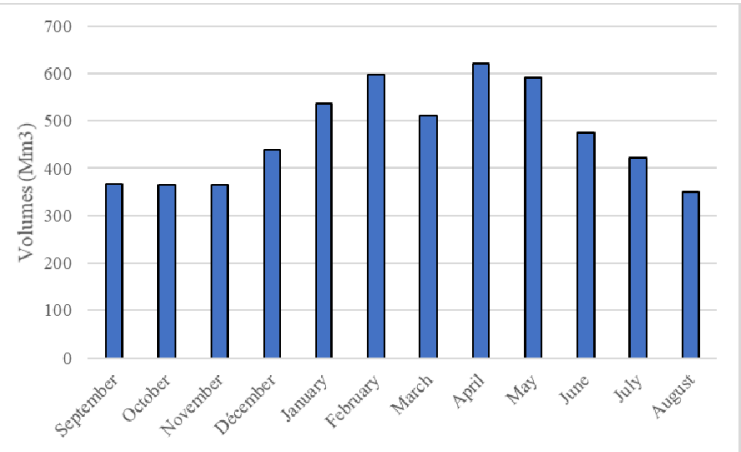

Fig. 13. Average monthly volumes of AEH'd reserves.

This paper demonstrated that remote sensing can be a valuable tool for water resources management. Flooded areas and stored volumes were estimated with a reasonable level of uncertainty. These uncertainties can be reduced using two approaches:

- Increasing the DEM accuracy by using pairs of stereoscopic photographs which are known to have been produced at the scale of Morocco during aerial missions dating from the early 1960s. In this case the spatial resolution of the DEM would be of the order of a metre [20].

- Increasing the resolution of optical images. An increase in the spatial resolution of the surface water layer could be tried by merging the channels used with the panchromatic channel. Thus, the spatial resolution would increase from $30 \mathrm{~m}$ to $15 \mathrm{~m}$.

Once these improvements, the OERHBA will have a cost-effective alternative way of monitoring inundated areas and water stored in the dam for a more effective management of the system.

\section{Conclusion}

The application of the MNDWI index on Landsat images has enabled us to study the spatiotemporal evolution of the extent of the AEH'd lake and the associated water volumes from 
$2002 / 2003$ to $2018 / 2019$. Results show that there is a significant retreat of the lake area in dry years up to 2008 , followed by a remarkable spatial increase in wet years. During this period, the water reserve varied between $200 \mathrm{Mm}^{3}$ and $800 \mathrm{Mm}^{3}$. These changes were shown to be consistent with regional climate trends. Optical images are hence valuable sources of information for the operational management of surface water reserves.

\section{References}

1. A. E. Boukhari, M. Naimi, M. Chikhaoui, and D. Raclot, Rev. Mar. Sci. Agron. Vét7, 288 (2019)

2. A. Lahlimi Alami, Agriculture 2030 : Quels Avenirs Pour Le Maroc 2030 ? (Haut Commissariat au Plan, n.d.), p. 108

3. F. Habets, The Conversation (2019)

4. M. Chahboune, A.S 10, 199 (2014)

5. B. Abdellaoui, A. Merzouk, M. Aberkan, and J. Albergel, Revue des sciences de l'eau 15, 737 (2005)

6. Brochure de l'Agence Du Bassin Hydraulique de l'Oum Er Rbia (n.d.), p. 28

7. A. Benhadi, 275 (1975)

8. Projet de Plan Directeur d'aménagement Intégré Des Ressoureces En Eau Du Bassin de l'Oum Er Rbia et Des Bassins Côtiers Atlantiques (2012), p. 19

9. A. Laouina, Gestion durable des ressources naturelles et de la biodiversité au Maroc (Haut Commissariat au Plan, 2006), p. 118

10. S. Biancamaria and Y. Kerr, La Météorologie 70 (2017)

11. T. El Orfi, M. El Ghachi, and S. Lebaut, in Renforcement de la résilience des hydrosystèmes face aux changements globaux: "de la mesure hydrologique aux modèles de gestion” (Béni Mellal - Maroc, 2020), pp. 47-52

12. A. Bentayeb and C. Leclerc, Ressources en Eau du Maroc, Tome III, Domaine atlasique et Sub-atlasique, Editions du service géologique du Maroc (1977)

13. S. K. McFeeters, International Journal of Remote Sensing 17, 1425 (1996)

14. H. Xu, International Journal of Remote Sensing 27, 3025 (2006)

15. K. V. Singh, R. Setia, S. Sahoo, A. Prasad, and B. Pateriya, Geocarto International 30, 650 (2015)

16. Y. Du, Y. Zhang, F. Ling, Q. Wang, W. Li, and X. Li, Remote Sensing 8, 354 (2016)

17. F. Menjour, F. Amraoui, and T. Remmal, in 6th International Conference on Cartography and GIS (Albena, Bulgaria, 2016), pp. 588-597

18. S. Szabó, Z. Gácsi, and B. Balázs, Landscape \& Environment 10, 194 (2016)

19. Q. Guo, R. Pu, J. Li, and J. Cheng, International Journal of Remote Sensing 38, 5430 (2017)

20. B. Sallak, Les risques hydrologiques d'inondations et la problématique d'aménagement des territoires de piémont: Cas du dir de Taghzirt à ZaouitEchiekh, Province de Béni Mellal, Maroc, Thèse de doctorat, Université de Lorraine, 2019 